\title{
The approachable reference desk How Norwich University Kreitzberg Library's desk got a new look
}

B uilt in the early 1990s, the Kreitzberg Library at Norwich University is an impressive building designed with cozy corners, large windows, a grand staircase, and an imposing reference desk to match. The desk, like many in academic libraries, was monstrous and built for keeping ready reference materials.

As years passed, less and less of the 10-by-18-foot desk was used, all while occupying significant space on the first floor. Librarians staffing the desk felt minuscule in comparison, and nearly two feet of desktop separated the seated librarian from patrons looking down at them, anxious about asking for help. The reference desk, meant to establish a commanding presence, became a barrier in more ways than one.

For several years, our reference team discussed an overall reconfiguration of the first floor, including the desk. In summer 2010, the conversation reignited, and we began throwing around the idea of a taller, more approachable desk. This discussion became a crusade to create a more welcoming reference desk matching the aesthetics of our carefully designed and much loved building.

The reference area now features a significantly smaller, 4-by-8-foot, transaction height desk with seating for students. The desk was also relocated and is now positioned in a more visible location closer to the entrance and adjacent to the circulation desk. This project also initiated a significant repurposing of first floor space, including a new seating area for patrons.

Many lessons were learned during this process. Our chronicle features tips and considerations for other library's pondering such an endeavor.

\section{Why redesign and not remove}

Norwich University is a small, private, military college in central Vermont. The on-campus student population of nearly 2,200 students is predominantly residential and comprises Corps of Cadets and civilian students. Even though virtual reference is increasing and in-person reference is declining, the desk remains an easily recognizable service point. There are many in the profession, however, who question the continued necessity of physical reference desks. So why did our library invest the time and effort to redesign our reference desk? Norwich has a very strong sense of history on campus; the university celebrates its bicentennial in 2019. Alumni are heartily loyal, and the library has an extremely active and financially supportive Friends group who would not take well to the desk disappearing entirely.

In a 2007 article, Steven Bell article noted that librarians "argue that owing to the unique nature of the institution and its culture, their students still want a desk where they can talk to librarians." ${ }^{1}$ This is certainly an easy card to play, but Norwich truly is very unique. With two-thirds of our undergraduates in the Corps, these young soldiers are cultivated with the mentality that asking questions is a weakness. We are dedicated to providing

Deborah Ahlers is head of reference and interlibrary loan, e-mail: deboraha@norwich.edu, and Heidi Steiner is distance learning librarian, e-mail: hsteiner@norwich. edu, at Norwich University in Northfield, Vermont

(C) 2012 Deborah Ahlers and Heidi Steiner 